\title{
A meta-analysis to evaluate the cellular processes regulated by the interactome of endogenous and over-expressed estrogen receptor alpha
}

\author{
Joana Simões ${ }^{1}$, Francisco M. Amado ${ }^{1,2}$, Rui Vitorino ${ }^{1,3, *}$ and Luisa A. Helguero ${ }^{1,3, *}$ \\ ${ }^{1}$ Mass Spectrometry Centre, QOPNA Research Unit, Department of Chemistry, Universidade de Aveiro, Campus Universitário \\ de Santiago, Aveiro, Portugal \\ ${ }^{2}$ School of Healh Sciences, Universidade de Aveiro, Portugal \\ ${ }^{3}$ Institute for Research in Biomedicine - iBiMED, Health Sciences Program, Universidade de Aveiro, Portugal \\ * These authors are Senior authors \\ Correspondence to: Luisa A. Helguero, email: luisa.helguero@va.pt \\ Keywords: estrogen receptor alpha, interactome, meta-analysis, breast cancer, mass spectrometry \\ Received: December 21,2014 Accepted: March 04, $2015 \quad$ Published: March 07, 2015
}

This is an open-access article distributed under the terms of the Creative Commons Attribution License, which permits unrestricted use, distribution, and reproduction in any medium, provided the original author and source are credited.

\section{ABSTRACT}

The nature of the proteins complexes that regulate ERa subcellular localization and activity is still an open question in breast cancer biology. Identification of such complexes will help understand development of endocrine resistance in ER+ breast cancer. Mass spectrometry (MS) has allowed comprehensive analysis of the ERa interactome. We have compared six published works analyzing the ERa interactome of MCF-7 and HeLa cells in order to identify a shared or different pathway-related fingerprint.

Overall, 806 ERa interacting proteins were identified. The cellular processes were differentially represented according to the ERa purification methodology, indicating that the methodologies used are complementary. While in MCF-7 cells, the interactome of endogenous and over-expressed ERa essentially represents the same biological processes and cellular components, the proteins identified were not over-lapping; thus, suggesting that the biological response may differ as the regulatory/participating proteins in these complexes are different. Interestingly, biological processes uniquely associated to ERa over-expressed in HeLa cell line included L-serine biosynthetic process, cellular amino acid biosynthetic process and cell redox homeostasis.

In summary, all the approaches analyzed in this meta-analysis are valid and complementary; in particular, for those cases where the processes occur at low frequency with normal ERa levels, and can be identified when the receptor is overexpressed. However special effort should be put into validating these findings in cells expressing physiological ERa levels.

\section{INTRODUCTION}

Sustained exposure to estradiol (E2) is associated with promotion and growth of breast cancer [1]. E2 action is mediated by estrogen receptors alpha and beta (ER $\alpha$ and ER $\beta$, respectively). These proteins belong to the nuclear hormone receptor family of transcription factors, and are structurally divided into six functional domains A-F $[2,3]$. The classical gene transactivation by
ER, involves ER binding to its ligands (e.g. E2), change in ER conformation, dimerization and recruitment of coregulator complexes at estrogen response elements (EREs), leading to transcriptional enhancement or repression of target genes. Nevertheless, ERs can also regulate gene expression through ERE-independent genomic action, without direct DNA binding, by modulating the function of other transcription factors through protein-protein interaction.The non-genomic ER actions are rapid and 
are frequently associated with the activation of various protein-kinase cascades in response to E2 [4, 5]. These non-genomic actions are possibly triggered through ERs located at the plasma membrane or, alternatively, associated to protein complexes located in the plasma membrane [6-8]. The genomic and non-genomic signal transduction pathways of activated ERs may connect with each other and involve multiple molecular complexes that modulate and/or mediate ER activity [9].

$\mathrm{ER} \alpha$ is the main mediator of E2-induced proliferation and survival of breast cancer cells. Approximately $70 \%$ of breast cancers are ER $\alpha+(\mathrm{ER}+)$, and this receptor remains the primary target for endocrine therapies that aim to block ER $\alpha$ genomic and non-genomic actions with antagonists (tamoxifen, raloxyfen, ICI 182 780), or inhibiting E2 synthesis with aromatase inhibitors $[10,11]$. Yet, about 50\% ER+ breast cancers acquire resistance to these type of therapy through different molecular mechanisms that target ER $\alpha$ [11-13]. It is widely accepted that acquired endocrine resistance is associated to sustained growth factor receptor signaling leading to ER ligand-independent activation [10]. However, only 10$15 \%$ endocrine resistant breast cancers show this type of alteration $[14,15]$ which suggests that other mechanisms are at play when cancers acquire resistance [16].

The nature of the protein complexes acting in concert with ERs to control its functions in the cell, in particular upon ligand-independent or non-genomic ER activation is still an open question in breast cancer biology $[17,18]$. Such information is of great interest because these proteins model the mechanisms of action of ERs involved not only in the promotion and progression of breast cancer, but also in the development of endocrine resistance. Further, they also constitute potential prognosis and follow-up markers. While in the past many laboratories have contributed to identify ER interacting proteins using a variety of experimental approaches and cell lines (a detailed list can be accessed at IntAct database: http:// www.ebi.ac.uk/intact/query/estrogen $\% 20$ receptor $\% 20$ alpha?conversationContext $=1$ ), the recent advance of high resolution mass spectrometry (MS) has allowed for a more comprehensive analysis of breast cancer proteomes and interactomes [19-21] including the ER $\alpha$ interactome $[17,22-26]$. Still, the cell type and context as well as the methodology used could lead to identification of different types of proteins /complexes, thereby hindering result extrapolation into generalized observations.

This study aimed to compare work carried out by others in which the ER $\alpha$ interactome was identified using two different cell lines: MCF-7 (ER+ breast cancer) and HeLa (ER-, cervical carcinoma) in order to identify a pathway-related fingerprint common to both cells lines or individually representing each of them. The MCF-7 cell line is an ideal model to study hormone response, whereas HeLa may not mimic the real ER signaling [27, 28]. This meta-analysis took into consideration the purification method, MS approach and whether ER $\alpha$ expression was endogenous or over-expressed.

\section{RESULTS AND DISCUSSION}

A PubMed literature search identified six papers describing the ER $\alpha$ interactome obtained using different experimental approaches; of these, four used the ER $\alpha$ positive MCF-7 cell line [endogenous ER $\alpha$ expression (2 papers) or over-expressed ER $\alpha$ (2 papers)], one used the ER $\alpha$ negative HeLa cell line (over-expressed ER $\alpha$ ) and one used both cell lines (over-expressed ER $\alpha$ ). The experimental conditions for each paper analyzed are described in Table 1 and a list of the proteins identified can be found in Supplementary Table S1.

Overall, the isolation methods used to purify $\mathrm{ER} \alpha$ were variable with three using ERE-repetition oligonucleotides as bait for $\operatorname{ER} \alpha$ pull down, two using TAP-ER $\alpha$ and one using ER $\alpha$ immunoprecipitation (Table 1). In addition, the cell treatment also varied between experiments with two papers treating cells with $10 \mathrm{nM}$ E2 prior protein extraction and the remaining four adding $\mathrm{E} 2$ to the protein extract during the incubation reaction (Table 1). Given the difference in the number of proteins identified between these two conditions, we could not reliably compare these two types of treatments and for our purposes considered all identifications as in "E2bound ER $\alpha$ ". In all experiments using MCF-7 cells, the growth medium was 5\% DCC which allowed for better comparison between the results generated by the different labs. On the other hand, results from HeLa cell line were obtained with cells grown in $10 \% \mathrm{FBS}$, which may contribute to additional variability between the results. In all these studies ER $\alpha$ interacting proteins were identified using different MS-based proteomic analysis (Table 1), gel-free (paper 2, 3, 4, 5 and 6), gel-based (paper 1) and coupling both approaches (paper 2). Gel-based techniques rely in the protein separation using gel electrophoresis including one dimensional electrophoresis (1DE) and twodimensional gel electrophoresis (2DE) $[33,34]$. The 2DE has also its limitations like requirement of huge amount of sample, inability to detect low abundance proteins, to resolve highly acidic/basic proteins and proteins with extreme size and/or hydrophobicity, which is the case of membrane proteins $[35,36]$. Additionally, technical bias induced by protein migration during the focusing step, or by gel staining, might difficult spot detection and their boundaries, making 2DE gel analysis a hard task which requires several replicates per sample [37]. Gel-free approach has been extensively developed and used in proteomic analysis because it allows overcoming some of the limitations of 2DE. This type of proteomic approach requires multiple liquid chromatography (LC) systems, essential to perform sample fraction of complex proteomes. Regarding disadvantages of MS, the low abundant proteins often will be lost because the mass 
A

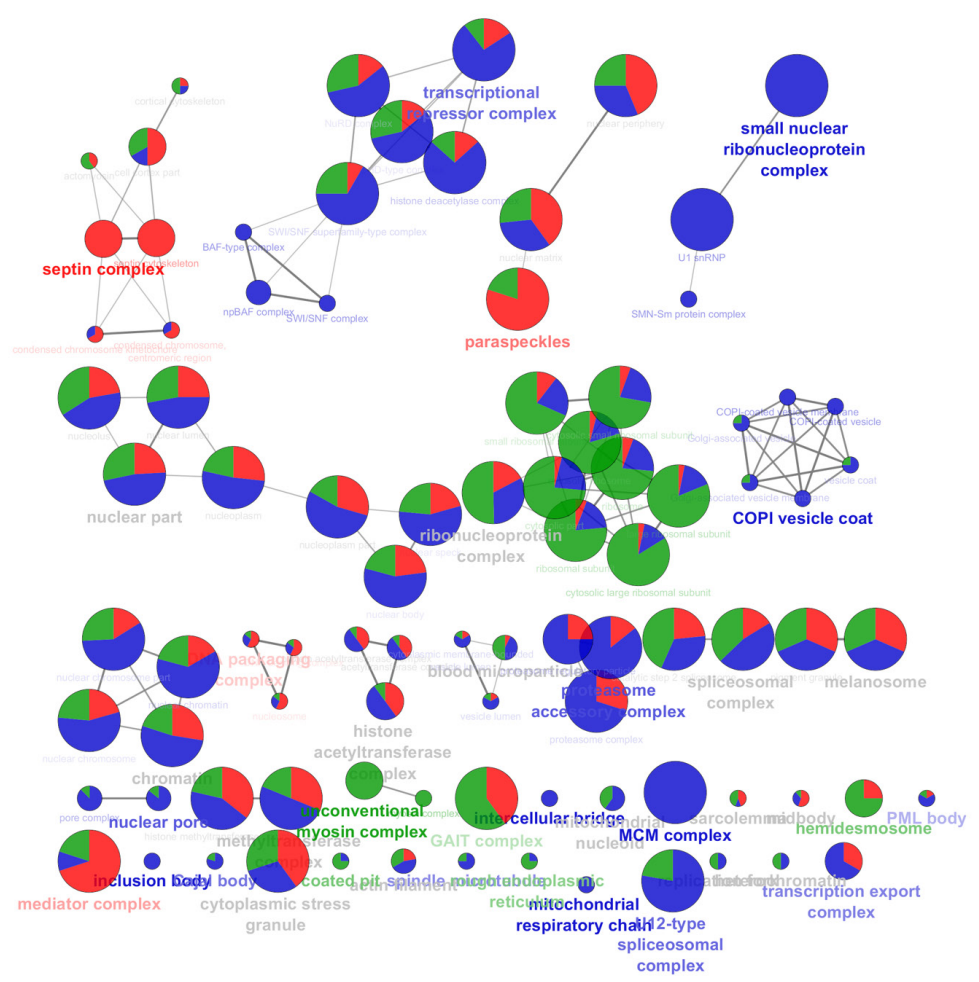

B
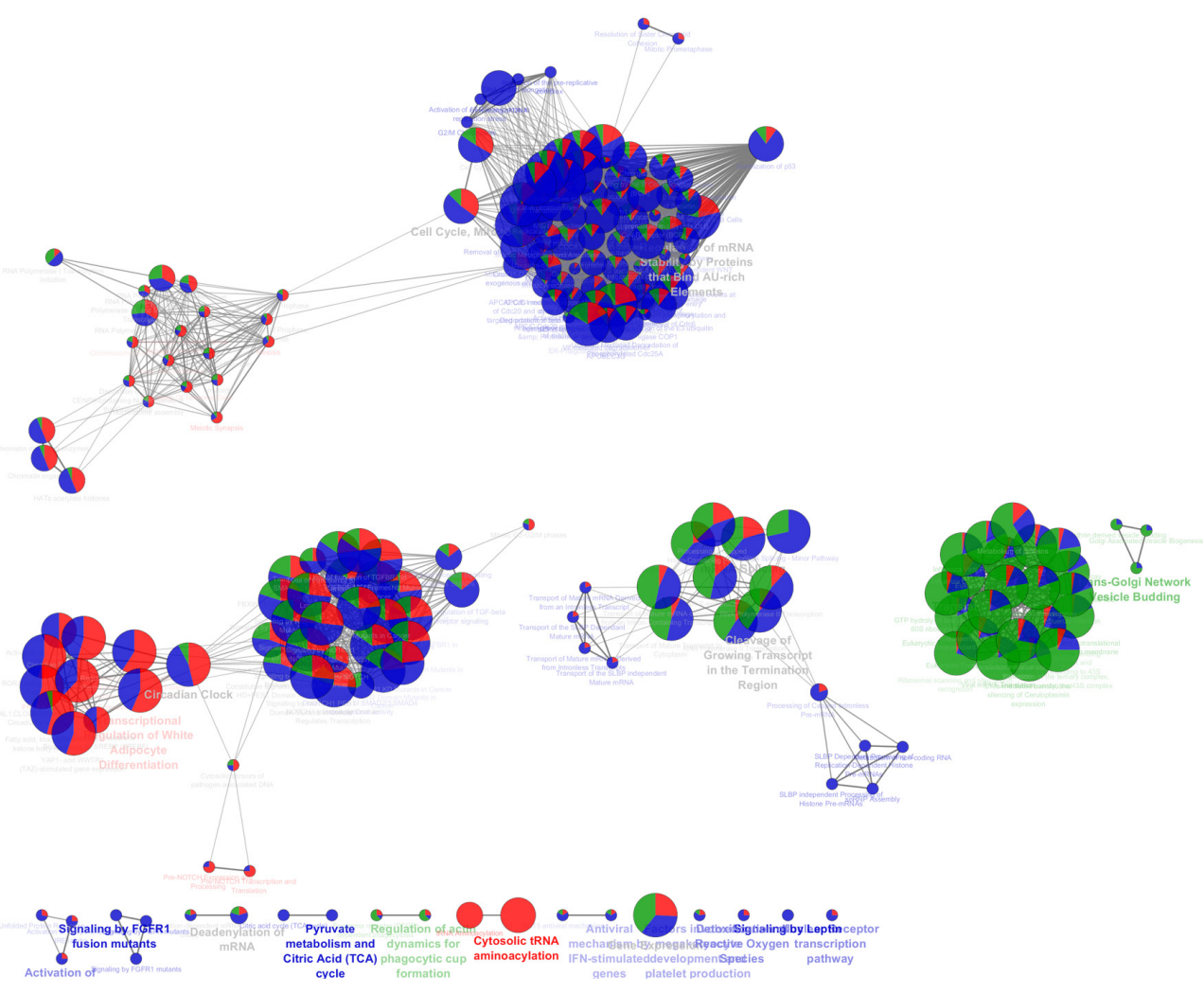

Figure 1: Comparison between MCF-7 cell ER interactome obtained with different purification methodologies: EREoligonucleotides (red), immunoprecipitation (blue) and TAP-ER $\alpha$ (green). The pie charts show the protein contribution from each methodology. A. Cellular component organization. B. Cellular pathways. 
Table 1: Papers which identified ER $\alpha$ interacting proteins using MS analysis.

\begin{tabular}{|c|c|c|c|c|c|c|}
\hline \# & Cell line & $\mathrm{ER} \alpha$ & Treatment & ER Isolation & MS methodology & Ref \\
\hline 1 & MCF-7 & endogenous & $\begin{array}{l}5 \% \text { DCC, } \\
48 \mathrm{hr}\end{array}$ & $\begin{array}{l}100 \mathrm{nM} \mathrm{E} 2,37^{\circ} \mathrm{C}, 45^{\prime}, \text { followed } \\
\text { by ERE-Sepharose }\end{array}$ & $\begin{array}{l}\text { 2DE, MALDI, TOF/ } \\
\text { TOF }\end{array}$ & Nalvarte, et al \\
\hline 2 & MCF-7 & overexpressed & $\begin{array}{l}5 \% \text { DCC, } \\
5 \text { days }\end{array}$ & $\begin{array}{l}10-8 \mathrm{M} \mathrm{E} 2 \text { added to protein } \\
\text { extract } 2 \mathrm{hr} \text { prior ER isolation } \\
\text { TAP-ER } \alpha\end{array}$ & $\begin{array}{l}\text { 2DE (DIGE), nanoLC, } \\
\text { ESI, QSTAR Elite } \\
\text { hybrid Q/TOF-MS }\end{array}$ & Ambrosino, et al \\
\hline 3 & HeLa & overexpressed & $10 \% \mathrm{FBS}$ & $\begin{array}{l}10 \mu \mathrm{M} \text { E2, } 10-20 \text { ' followed by } \\
\text { EREbinding and factionation in } \\
\text { agarose gel }\end{array}$ & $\mu \mathrm{LC}, \mathrm{ESI}, \mathrm{MS} / \mathrm{MS}$ & $\begin{array}{l}\text { Schultz-Norton, } \\
\text { et al }\end{array}$ \\
\hline 4 & MCF-7 & overexpressed & $\begin{array}{l}5 \% \text { DCC, } \\
5 \mathrm{~d}\end{array}$ & $\begin{array}{l}10 \mathrm{nM} \text { E2, } 2 \mathrm{hr} \text { followed by } \\
\text { TAP-ER } \alpha\end{array}$ & $\begin{array}{l}\text { nanoLC, ESI, QSTAR } \\
\text { Elite hybrid Q/TOF- } \\
\text { MS }\end{array}$ & Tarallo, et al \\
\hline 5 & MCF-7 & endogenous & $\begin{array}{l}5 \% \text { DCC }+ \\
\mathrm{E} 2,3 \text { days }\end{array}$ & $\begin{array}{l}\text { Crosslinking folowed by } \\
\text { Immunoprecipitation }\end{array}$ & $\begin{array}{l}\text { nanoLC, LTQ } \\
\text { Velos-Orbitrap MS }\end{array}$ & Mohammed, et al \\
\hline 6 & $\begin{array}{l}\mathrm{MCF}-7 \\
\mathrm{HeLa}\end{array}$ & overexpressed & $\begin{array}{l}5 \% \mathrm{DCC}+ \\
10 \mathrm{nM} \mathrm{E} 2, \\
72 \mathrm{hr}\end{array}$ & $\begin{array}{l}\text { ERE-magnetic } \\
\text { beads }\end{array}$ & 1DE, nanoLC-MS/MS & Foulds, et al \\
\hline
\end{tabular}

spectrometer can only sequence a limited number of peptides in a given time window and these will normally be the most intense peaks, whereas low abundant peaks will not be sequenced although it is possible to partially overcome this problem [34].

Thus, in light of the high divergence between the experimental approaches used, we addressed the following questions with the aim to identify the processes, pathways and cellular components most represented: 1) What type of protein enrichment is associated to the isolation / MS approach?; 2) Is the ER $\alpha$ interactome different if $\mathrm{ER} \alpha$ is endogenous or over-expressed in MCF-7 cells? and 3) Is there any difference between the ER $\alpha$ interactome in an $\mathrm{ER} \alpha+$ compared to an ER $\alpha$ - cellular background?

\section{Comparison between different ER $\alpha$ purification methodologies}

Comparison of ER $\alpha$ purification using EREoligonucleotides as bait [(paper 1 (ERE-Sepharose) and 6 (ERE-magnetic beads) in MCF-7 cells and paper 3 (ERE (Agarose) in HeLa cells; Table 1)] disclosed only one identification in common when comparing MCF-7 cells (NCOA2) and 15 shared identifications between MCF-7 using ERE-Sepharose and HeLa cells using ERE / Agarose (Supplementary Figure 1). This suggests that the different incubation procedures with E2, that is added during cell growth (paper 6) or added directly to the incubation reaction (papers 1 and 3; Table 1) possibly had an effect on the type of interacting protein isolated. Of a total of 96
(ERE), 129 (TAP) and 234 (IP) identifications in MCF-7 cells, 15 proteins were identified using ERE or TAP, 8 with ERE or IP, 4 with TAP and IP and none simultaneously by the three methodologies (Supplementary Figures 1 and 3). Further, when the cellular components represented by the three methodologies in MCF-7 cells were compared, Septin complex and paraspeckles were almost uniquely represented by ERE-purified ER $\alpha$; GAIT complex and hemidesmosome by TAP-ER $\alpha$, and mitochondrial respiratory chain, inclusion body, COPI vesicle coat, small nuclear ribonucleoprotein complex and MCM complex, were exclusively observed when ER $\alpha$ was immunoprecipitated (Figure 1A and Supplementary Table 2). Consequently, several pathways are differentially represented according to the ER purification methodology (Figure 1B and Supplementary Table 2).

This analysis clearly indicates that the methodologies used are complementary. Therefore, we proceeded to group the data in order to compare the interactomes of endogenous $v s$ over-expressed ER $\alpha$ in $\mathrm{MCF}-7$ cells and over-expressed ER $\alpha$ in MCF-7 vs HeLa cells.

\section{Interactome of endogenous and over-expressed ER $\alpha$ in MCF-7 cell line}

Three hundred and thirty-eight proteins were found associated to endogenous $\mathrm{ER} \alpha$ and 166 proteins to overexpressed ER $\alpha$; of these only 24 proteins were common to both conditions (Figure 2A and Supplementary 
Figure 3). The stronger interaction evidence according to STRING (Figure 2B) occurs directly with the corepressors NRIP1 and HDAC2, and the co-activators NCOA2, NCOA3, DDX17 and DDX3X (SP1-dependent). Through interaction with the apoptosis suppressor NPM1, ER $\alpha$ is also associated to MYBBP1A and NCL1 which can either activate or repress transcription. Also, through NPM1, ER $\alpha$ may associate with SYNCRIP (heterogeneous nuclear ribonucleoprotein) and DHX9 (ATP-dependent helicase) both members of the CRDmediated complex that promotes c-myc mRNA stability. The GO annotation in terms of cellular component (CC) using Panther (pantherdb.org) were cytoskeleton (22\%), intracellular (22\%) and ribonucleoprotein complex (56\%). The biological processes most represented by these proteins where metabolic process (carbohydrate metabolic process, 7\%; cellular aminoacid metabolic process, $7 \%$, lipid metabolic process, 3.4\%; nucleobase-containing compound metabolic process), $55 \%$; and protein metabolic process (translation), 26\%.

Proteins interacting only with endogenous ER $\alpha$ were localized at transcription export complex (TREX complex), proteasome accessory complex, small nuclear ribonucleoprotein complex and MCM complex (SupplementaryTable 3). In higher eukaryotes, the TREX complex recruitment is linked to mRNA splicing and/ or capping [38, 39]. Even though, it is currently unclear whether the transport and processing of every mRNA occurs in the same way in every cell, this mechanism is conserved among species. Moreover, perturbations in the factors that are essential for mRNA nuclear export are linked to different diseases [40]. Therefore, the lack of representation by the over-expressed $\mathrm{ER} \alpha$ interactome is surprising. The proteasome accessory complex caps one or both ends of the proteasome core complex and regulates entry into, or exit from, the proteasome; this may indicate differential turn-over of over-expressed ER $\alpha$ as compared to the endogenous protein. The MCM (mini chromosome maintenance) complex, has a role in both the initiation and the elongation phases of eukaryotic DNA replication, specifically the formation and elongation of the replication fork and are therefore essential for cell cycling. This could explain why MCF-7 cells transfected with $\mathrm{ER} \alpha$, fail to increase proliferation in response to E2 [41]. Yet, proliferation remains a major prognostic factor in ER $\alpha+$ breast cancer [42] and these data shows a direct
A
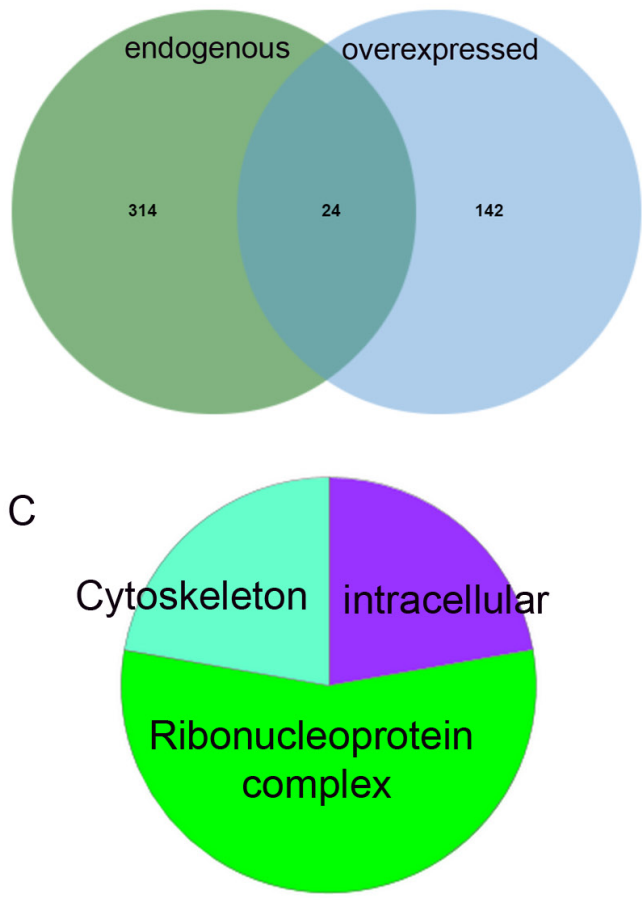

B

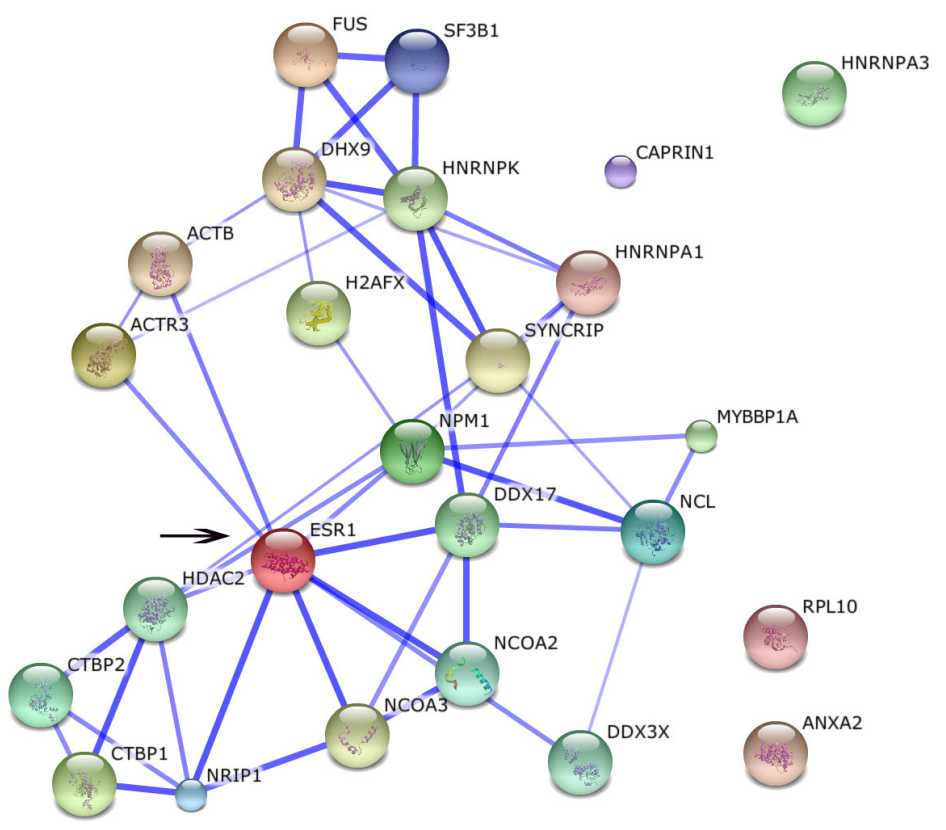

Figure 2: Interactome of MCF-7 cells expressing endogenous and over-expressed ERa. A.Venn diagram representing overlapped and unique proteins interacting with endogenous or overexpressed ER $\alpha$. B. Protein-protein interaction network extracted from STRING, depicting the shared interacting proteins between endogenous and overexpressed ER $\alpha$ (ESR1: arrow). The confidence view shows stronger associations represented by thicker lines and is based on co-occurrence, co-expression, experimental data and database. Medium confidence (Score=0.4). C. Cellular component distribution of shared interacting proteins between endogenous and overexpressed $\mathrm{ER} \alpha$ according to pantherdb.org. 
association between endogenous $\mathrm{ER} \alpha$ and the MCM complex. In addition, a higher representation of cellular complexes associated to the nucleus and chromatin, including transcriptional repressor complex, histone deacetylase complex, U12-type spliceosomal complex and paraspeckles was also observed in the interactome of endogenous $\mathrm{ER} \alpha$. While the interacting proteins with over-expressed ER $\alpha$ were less represented in these complexes, except for a higher percentage representing the mediator complex (Supplementary Table 3). Mediator relays signals from transcription factors directly to the pol II enzyme, thereby regulating pol II activity and facilitating transcription factor-dependent regulation of gene expression. The lower $\%$ of these associated factors in the interactome of endogenous $\mathrm{ER} \alpha$, as well as the observation that MED15 and MED27 (interacting with endogenous $\mathrm{ER} \alpha$ ) are not found among the mediator complex proteins identified with over-expressed ER $\alpha$ is surprising, and suggests that gene regulation by ER $\alpha$ in this two settings differs.

The analysis of BPs showed that tRNA aminoacylation for protein translation was uniquely represented by the endogenous ER $\alpha$ interactome (Supplementary Table 3 ). Also, the interacting proteins with endogenous $\mathrm{ER} \alpha$ showed more representation of protein folding, DNA metabolic process, chromosome organization, regulation of cell death and cellular response to DNA damage stimulus. On the other hand, the interacting proteins with over-expressed ER $\alpha$ were more representative of intracellular steroid hormone receptor signalling pathway, nuclear-transcribed mRNA catabolic process, nonsense-mediated decay (a quality control mechanism which eliminates mRNA transcripts with premature stop codons) and SRP-dependent cotranslational protein targeting to membrane. The low representation of these two BPs by the interactome of endogenous $\mathrm{ER} \alpha$ (23 and $20 \%$ vs 78 to $82 \%$ in overexpressed $\mathrm{ER} \alpha$ ) suggests that they possibly occur with lower frequency when $\mathrm{ER} \alpha$ is expressed at physiological levels. Moreover, Reactome pathways including Cytosolic tRNA aminoacylation, RNA Polymerase I Promoter Clearance and Regulation of mRNA Stability by Proteins that Bind AU-rich Elements were significantly represented by proteins interacting with endogenous ER $\alpha$; whereas Translation was significantly represented in the interactome of over-expressed ER $\alpha$ (Supplementary Table $3)$.

Regarding the lower representation of processes and complexes by over-expressed ER $\alpha$, it can be argued that this is directly related to less number of proteins identified for this condition. However, even the proteins identified interacting with endogenous or over-expressed ER $\alpha$ for a defined process were, in most cases, not overlapping. Therefore, we conclude that in MCF-7 cells, the interactome of over-expressed ER $\alpha$ essentially represents the same BPs and CCs; however, the biological response may differ as the regulatory/participating proteins in these complexes are different. This may explain differential transactivation mechanisms between endogenous (liganddependent) and over-expressed ER $\alpha$ showing significant ligand-independent activity which may interact with mediator complexes in a ligand-independent manner, in a similar way as shown for over-expressed PPARs [43]. In addition, over-expression of ERs can lead to differential regulation of membrane proteins, such as cell adhesion proteins, through transcription-independent mechanisms $[44,45]$. While, these effects possibly also occur at lower levels in the physiologic scenario [46, 47], over-expressed $\mathrm{ER} \alpha$ results in higher interaction with SRP targeting to the membrane possibly making this effect more evident.

\section{Interactome of over-expressed ER $\alpha$ in MCF-7 and in HeLa cell lines}

One-hundred and sixty-six proteins were identified interacting with $\mathrm{ER} \alpha$ in MCF-7 cells and 286 proteins interacting with ER $\alpha$ in HeLa cells. Only 25 proteins were shared by both cell lines (Figure 3A and Supplementary Figure 4). Among the shared interactors by MCF-7 and HeLa cells were components of the mediator complex (CCNC, CDK8, MED1, MED12, MED13, MED26), several co-activators (NCOA1, NCOA2, NCOA3, NCOA6, CREBBP, FOXO1, EP300, TADA3) and corepressors (NRIP1, CTBP1, CTBP2) all which could directly interact with $\mathrm{ER} \alpha$ (Figure 3B). These proteins were intracellular (50\%), organelle (of which 66\% are in the cytoplasm and $33 \%$ in the nucleus), and macromolecular complexes $(20 \%$, including protein and ribonucleoprotein complexes) (Figure 3C). The BPs over-represented according to Panther were cell process (cell communication, cell cycle, cell proliferation and cytokinesis), 17\%; biosynthetic process (carbohydrate metabolic process, cellular amino acid metabolic process, nucleobase-containing compound metabolic process and protein metabolic process), 30\%; and biological regulation (regulation of transcription from Pol II promoter), 17\%.

The $\mathrm{CC}$ by $\mathrm{ER} \alpha$ interacting proteins in $\mathrm{MCF}$ 7 cells uniquely represented unconventional myosin complex and hemidesmosome (Supplementary Table 4), suggesting a role of ER $\alpha$ in regulating cell movement and localization at the cell adhesion contacts. Experimental evidence suggesting such regulation may be independent of ER transcriptional activation has been reported [48, 49]. Catalytic step 2 spliceosome, mediator complex and ribonucleoprotein complex were also more represented by the interactome from MCF-7 cells. On the other hand, protein phosphatase type $2 \mathrm{~A}$ complex (PP2A), proteasome complex, eukaryotic translation elongation factor 1 complex and COPI vesicle coat were uniquely over-represented by the interactome of HeLa cells. PP2A expression is upstream of ER expression and contributes 
to the $\mathrm{ER} \alpha+$ phenotype in breast cancer cell lines through stabilization of ER mRNA [50] and ER-non genomic activation of PP2A has also been shown in vascular smooth muscle cells (with endogenous ER) [51]. COPI coated vesicles are involved in retrograde transport to the endoplasmic reticulum from the Golgi network, again suggesting that $\mathrm{ER} \alpha$ regulates membrane proteins.

Among BPs, the ones represented by similar amount of proteins in MCF-7 cells compared to HeLa cells were related to RNA regulation, including: intracellular receptor signalling pathway, nucleobase-containing compound catabolic process, mRNA metabolic process and posttranscriptional regulation of gene expression (Supplementary Table 4). Histone acetylation and protein folding were mostly represented by the HeLa interactome. Interestingly, BPs uniquely associated to $\mathrm{ER} \alpha$ overexpressed in HeLa cell line included L-serine biosynthetic process, cellular amino acid biosynthetic process and cell redox homeostasis, clearly suggesting that in this ER $\alpha$ background, many proteins involved in cell metabolism and energy homeostasis can interact with over-expressed $\mathrm{ER} \alpha$, with consequences regarding cell growth and proliferation. Protein deneddylation was also uniquely represented by the HeLa interactome. Deneddylation of proteins removes the Nedd 8 moiety from cullins, thereby preventing cullins from organizing ubiquitin ligase (E3) complexes in order to target cellular proteins for proteasomal degradation [52]. As ER $\alpha$ is itself targeted for proteasomal degradation by ubiquitin E3 ligases [53], in HeLa cells over-expressing ER $\alpha$, this interaction may favour $\mathrm{ER} \alpha$ stability.

The interactome in HeLa cells was associated to pathways rarely observed in MCF-7 cells: Glycolysis, Prefoldin mediated transfer of substrate to CCT/TriC, Destabilization of mRNA by AUF1 (hnRNP D0), Cytosolic tRNA aminoacylation, Sulfur amino acid metabolism. Regarding the ER $\alpha$ interactome of MCF-7 cells, the association to transcription and mRNA splicing was more represented than in HeLa cells (Supplementary Table 4). Gene expression was equally represented in both cell lines; however, the proteins associated to these pathways were in most cases not over-lapping.
A

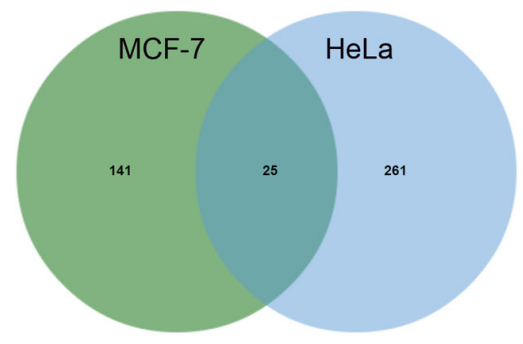

C

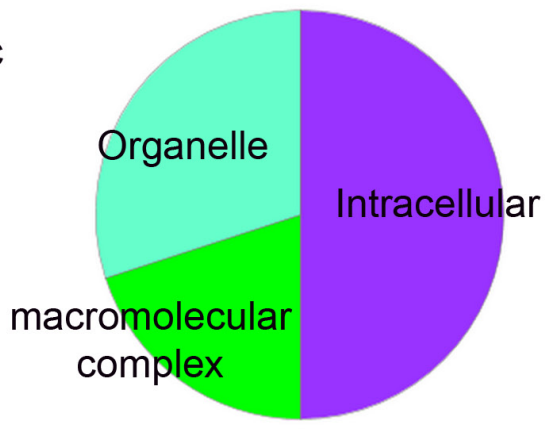

B

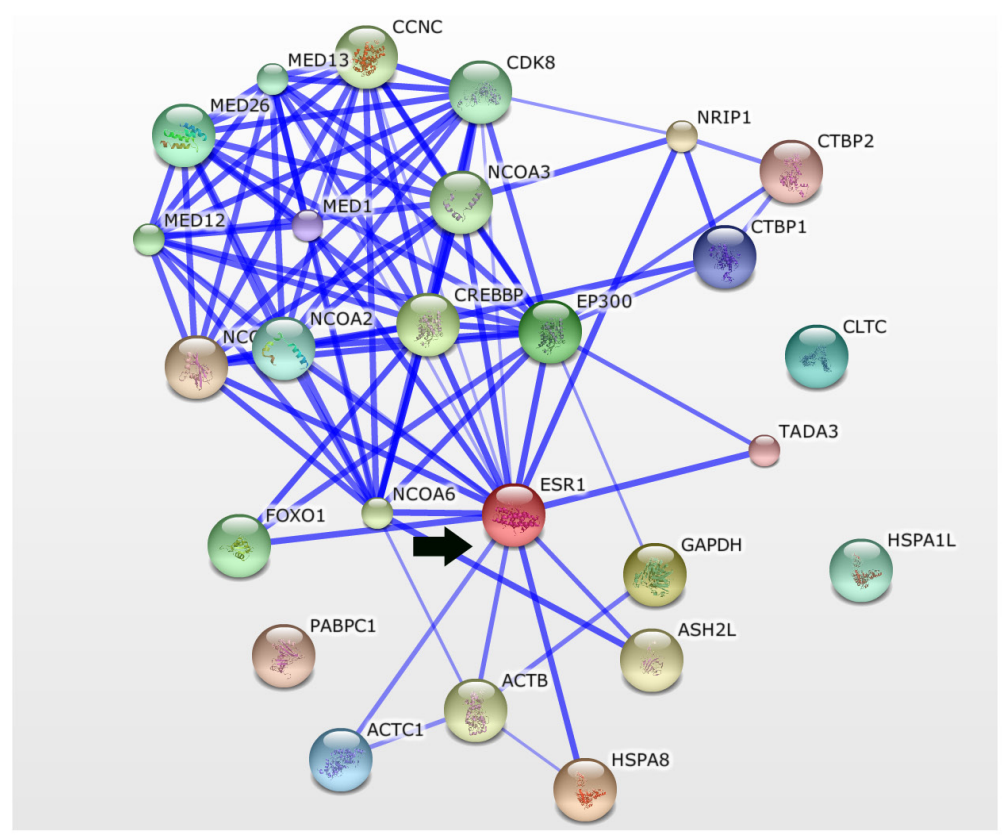

Figure 3: Interactome of MCF-7 and HeLa cells with over-expressed ER $\boldsymbol{\alpha}$. A.Venn diagram representing overlapped and unique proteins interacting with overexpressed ER $\alpha$ in MCF-7 and HeLa cells. B. Protein-protein interaction network extracted from STRING, depicting the shared interacting proteins between MCF-7 and HeLa cells ER $\alpha$ (ESR1: arrow). The confidence view shows stronger associations represented by thicker lines and is based on co-occurrence, co-expression, experimental data and database. Medium confidence (Score=0.4). C. Cellular component distribution of shared interacting proteins between overexpressed ER $\alpha$ in MCF-7 and HeLa cells according to pantherdb.org. 


\section{CONCLUSION}

In this work we addressed the question of whether endogenous and exogenous ER $\alpha$ interact with similar cellular proteins and regulate the same biological processes. This question is relevant, given that for analysis of interacting proteins and gene expression, over-expressed ER $\alpha$ is generally used. Indeed, with the over-expressed receptor, the biological effects observed are clearer than when analyzing endogenous ER $\alpha$ levels. Nevertheless, they may not reflect the physiological interactions occurring in ER $\alpha$ expressing cells. On the other hand, it can be argued that those interactions occur naturally, but at such low frequency that they are not detected during MS sequencing.

The different purification methodologies will enrich in specific ER $\alpha$ containing complexes and therefore highlight different pathways. Interestingly, the ER $\alpha$ interactome disclosed ER $\alpha$ possible presence in complexes across all cell organelles and subcellular localizations; thus, supporting the idea that ER $\alpha$ is not merely a transcription factor and that its activation leads to biological effects regulated transcriptionally and nontranscriptionally.

Therefore, while all the approaches analyzed in this meta-analysis are valid and complementary, special effort should be put into validating findings from cell lines with over-expressed ER $\alpha$ in cells expressing natural levels of the receptor. Such actions will no doubt advance our understanding of ER signalling and uncover novel potential targets to revert endocrine resistance.

\section{METHODS}

In order to analyze the ER $\alpha$ interactome, database searching was carried out on PubMed, Google Scholar and Web of Knowledge using the keywords "ER $\alpha$ interactome", "ER $\alpha$ interacting proteins", "ER $\alpha$ associated proteins", "ER $\alpha$ interactors" and "ER $\alpha$ mass spectrometry" for articles studying the interactome of $\mathrm{ER} \alpha$ using MS in breast cancer cell lines or mammary epithelial cells. Six papers were identified which contained a full and comprehensive list of interacting proteins and which were used for this meta-analysis. For each identification, the accession number, protein name and gene name were extracted from the Uniprot (http:// www.uniprot.org/) and Panther (http://www.pantherdb. org/) databases (Table 1 and Supplementary Table S1). In order to identify statistically over-represented Gene Ontology terms corresponding to Biological Process (BP), Cellular Component (CC) and pathways, we used the Cytoscape 3.1.0 (http://www.cytoscape.org/) [29] software with ClueGo v2.1.5 and CluePedia v1.1.5 plugins $[30,31]$. In all analysis, filters were set to Go tree interval with 3 minimum and 8 maximum levels; Go term/ Pathway selection with 3 minimum genes and $8 \%$ genes; medium network specificity (Kappa score $=0.4)$ and over-representation was considered significant if $p<0.05$. STRING database 9.1 (Search Tool for the Retrieval of Interacting Genes) [32] (http://string-db.org/) was also used to provide a grid of possible ER $\alpha$ containing protein complexes (Kappa score $=0.4$ ).

\section{ACKNOWLEDGEMENTS}

This work was supported by Federal funds through Programa Operacional Temático Factores de Competitividade (COMPETE) with co-participation from the European Community Fund (FEDER) and national funds through Fundação para a Ciência e Tecnología (FCT) under the projects PTDC/SAU-ONC/112671/2009 and PTDC/SAU-ONC/118346/2010 (LAH). The Mass Spectrometry Center, within the Organic Chemistry and Natural Products (QOPNA) research unit is founded by the University of Aveiro, FCT, European Union, QREN, FEDER and COMPETE projects PEst-C/ QUI/UI0062/2013 and RNEM (Rede Nacional de Espectrometria de Massa).

\section{CONFLICT OF INTEREST}

The authors declare no potential conflict of interest

\section{REFERENCES}

1. Russo J, Russo, IH. The role of estrogen in the initiation of breast cancer. J steroid biochem mol biol. 2006; 102: 89-96.

2. Koehler KF, Helguero, LA, Haldosen, LA, Warner M, Gustafsson JA. Reflections on the discovery and significance of estrogen receptor beta. Endocr Rev. 2005; 26: 465-478.

3. Kumar R, Zakharov MN, Khan SH, Miki R, Jang H, Toraldo G, Singh R, Bhasin S, Jasuja R. The dynamic structure of the estrogen receptor. J Amino Acids. 2011: 812540.

4. Sanchez R, Nguyen D, Rocha W, White JH, Mader S. Diversity in the mechanisms of gene regulation by estrogen receptors. Bioessays. 2002. 24: 244-254.

5. Shupnik MA. Crosstalk between steroid receptors and the c-Src-receptor tyrosine kinase pathways: implications for cell proliferation. Oncogene. 2004. 23: 7979-7989.

6. Pappas TC, Gametchu B, Watson CS. Membrane estrogen receptors identified by multiple antibody labeling and impeded-ligand binding. Faseb j. 1995. 9: 404-10.

7. Heldring N, Pike A, Andersson S, Matthews J, Cheng G, Hartman J, Tujague M, Strom A, Treuter E, Warner M, Gustafsson JA. Estrogen receptors: how do they signal and what are their targets. Physiol Rev. 2007. 87: 905-931.

8. Migliaccio A, Di Domenico M, Castoria G, de Falco A, Bontempo P, Nola E, Auricchio F. Tyrosine kinase/p21ras/ MAP-kinase pathway activation by estradiol-receptor 
complex in MCF-7 cells. Embo j, 1996. 15: 1292-1300.

9. Bjornstrom L, Sjoberg M. Mechanisms of estrogen receptor signaling: convergence of genomic and nongenomic actions on target genes. Mol Endocrinol. 2005. 19: 833-842.

10. Musgrove EA, Sutherland RL. Biological determinants of endocrine resistance in breast cancer. Nat Rev Cancer. 2009. 9: 631-643.

11. Giuliano M, Schifp R, Osborne CK, Trivedi MV. Biological mechanisms and clinical implications of endocrine resistance in breast cancer. Breast. 2011. 20 Suppl 3: S42-S49.

12. Garcia-Becerra R, Santos N, Diaz L, Camacho J. Mechanisms of Resistance to Endocrine Therapy in Breast Cancer: Focus on Signaling Pathways, miRNAs and Genetically Based Resistance. Int J Mol Sci. 2012. 14: 108145.

13. Tyson JJ, Baumann WT, Chen C, Verdugo A, Tavassoly I, Wang Y, Weiner LM, Clarke R. Dynamic modelling of oestrogen signalling and cell fate in breast cancer cells. Nat Rev Cancer. 2011. 11: 523-532.

14. Dowsett M, Johnston S, Martin LA, Salter J, Hills M, Detre S, Gutierrez MC, Mohsin SK, Shou J, Allred DC, Schiff R, Osborne CK, Smith I. Growth factor signalling and response to endocrine therapy: the Royal Marsden Experience. Endocr Relat Cancer. 2005. 12 Suppl 1: S113-S117.

15. Gutierrez MC, Detre S, Johnston S, Mohsin SK, Shou J, Allred DC, Schiff R, Osborne CK, Dowsett M. Molecular changes in tamoxifen-resistant breast cancer: relationship between estrogen receptor, HER-2, and p38 mitogenactivated protein kinase. J Clin Oncol. 2005. 23: 2469-2476.

16. Miller TE, Ghoshal K, Ramaswamy B, Roy S, Datta J, Shapiro CL, Jacob S, Majumder S. MicroRNA-221/222 confers tamoxifen resistance in breast cancer by targeting p27Kip1. J Biol Chem. 2008. 283: 29897-29903.

17. Ambrosino C, Tarallo R, Bamundo A, Cuomo D, Franci G, Nassa G, Paris O, Ravo M, Giovane A, Zambrano N, Lepikhova T, Janne OA, et al. Identification of a hormoneregulated dynamic nuclear actin network associated with estrogen receptor alpha in human breast cancer cell nuclei. Molecular \& Cellular Proteomics. 2010. 9: 1352-1367.

18. Gronemeyer H, Gustafsson JA, Laudet V. Principles for modulation of the nuclear receptor superfamily. Nat Rev Drug Discov. 2004. 3: 950-964.

19. Biarc J, Gonzalo P, Mikaelian I, Fattet L, Deygas M, Gillet G, Lemoine J, Rimokh R. Combination of a discovery LC-MS/MS analysis and a label-free quantification for the characterization of an epithelial-mesenchymal transition signature. J Proteomics. 2014. 110: 183-194.

20. Groessl M, Slany A, Bileck A, Gloessmann K, Kreutz D, Jaeger W, Pfeiler G, Gerner, C. Proteome profiling of breast cancer biopsies reveals a wound healing signature of cancer-associated fibroblasts. J Proteome Res. 2014. 13: 4773-4782.
21. Zaman N, Giannopoulos PN, Chowdhury S, Bonneil E, Thibault P, Wang E, Trifiro M, Paliouras M. ProteomicCoupled-Network Analysis of T877A-Androgen Receptor Interactomes Can Predict Clinical Prostate Cancer Outcomes between White (Non-Hispanic) and AfricanAmerican Groups. PLoS One. 2014. 9: e113190.

22. Nalvarte I, Schwend T, Gustafsson JA. Proteomics analysis of the estrogen receptor alpha receptosome. Mol Cell Proteomics. 2010. 9: 1411-22.

23. Schultz-Norton JR, Ziegler YS, Likhite VS, Yates JR, Nardulli AM. Isolation of novel coregulatory protein networks associated with DNA-bound estrogen receptor alpha. BMC Mol Biol. 2008. 9: 1-2.

24. Tarallo R, Bamundo A, Nassa G, Nola E, Paris O, Ambrosino C, Facchiano A, Baumann M, Nyman TA, Weisz, A. Identification of proteins associated with ligandactivated estrogen receptor alpha in human breast cancer cell nuclei by tandem affinity purification and nano LC-MS/ MS. Proteomics. 2011. 11: 172-179.

25. Mohammed H, D'Santos C, Serandour AA, Ali HR, Brown GD, Atkins A, Rueda O M, Holmes KA, Theodorou V, Robinson JL, Zwart W, Saadi A, Ross-Innes CS, et al. Endogenous purification reveals GREB1 as a key estrogen receptor regulatory factor. Cell Rep. 2013. 3: 342-349.

26. Foulds CE, Feng Q, Ding C, Bailey S, Hunsaker TL, Malovannaya A, Hamilton R A., Gates LA, Zhang Z, Li C, Chan D, Bajaj A, Callaway CG, et al. Proteomic analysis of coregulators bound to ERalpha on DNA and nucleosomes reveals coregulator dynamics. Mol Cell. 2013. 51: 185-199.

27. Levenson AS, Jordan VC. MCF-7: the first hormoneresponsive breast cancer cell line. Cancer Res. 1997. 57: 3071-3078.

28. Holliday DL, Speirs V. Choosing the right cell line for breast cancer research. Breast Cancer Res. 2011. 13: 215.

29. Shannon P, Markiel A, Ozier O, Baliga NS, Wang JT, Ramage D, Amin N, Schwikowski B, Ideker T. Cytoscape: a software environment for integrated models of biomolecular interaction networks. Genome Res. 2003. 13: 2498-2504.

30. Bindea G, Mlecnik B, Hackl H, Charoentong P, Tosolini M, Kirilovsky A, Fridman, WH, Pages F, Trajanoski Z, Galon J. ClueGO: a Cytoscape plug-in to decipher functionally grouped gene ontology and pathway annotation networks. Bioinformatics. 2009. 25: 1091-1093.

31. Bindea G, Galon J, Mlecnik B. CluePedia Cytoscape plugin: pathway insights using integrated experimental and in silico data. Bioinformatics. 2013. 29: 661-663.

32. Franceschini A, Szklarczyk D, Frankild S, Kuhn M, Simonovic M, Roth A, Lin J, Minguez P, Bork P, von Mering C, Jensen L. J. STRING v9.1: protein-protein interaction networks, with increased coverage and integration. Nucleic Acids Res. 2013. 41(Database issue): D808-D815.

33. Abdallah C, Dumas-Gaudot E, Renaut J, Sergeant K. Gelbased and gel-free quantitative proteomics approaches at a 
glance. Int J Plant Genomics. 2012. 2012: 494572.

34. Roepstorff P. Mass spectrometry based proteomics, background, status and future needs. Protein Cell. 2012. 3: 641-647.

35. Paul D, Kumar A, Gajbhiye A, Santra MK, Srikanth R. Mass spectrometry-based proteomics in molecular diagnostics: discovery of cancer biomarkers using tissue culture. Biomed Res Int. 2013. 2013: 783131.

36. Galvao ER, Martins LM, Ibiapina JO, Andrade HM, Monte SJ. Breast cancer proteomics: a review for clinicians. J Cancer Res Clin Oncol. 2011. 137: 915-925.

37. Bland AM, Janech MG, Almeida JS, Arthur JM. Sources of variability among replicate samples separated by twodimensional gel electrophoresis. J Biomol Tech. 2010. 21: 3-8.

38. Cheng H, Dufu K, Lee CS, Hsu JL, Dias A, Reed R. Human mRNA export machinery recruited to the 5' end of mRNA. Cell. 2006. 127: 1389-1400.

39. Zhou Z, Luo MJ, Straesser K, Katahira J, Hurt E, Reed $\mathrm{R}$. The protein Aly links pre-messenger-RNA splicing to nuclear export in metazoans. Nature. 2000. 407: 401-405.

40. Carmody SR, Wente SR. mRNA nuclear export at a glance. J Cell Sci. 2009. 122: 1933-1937.

41. Fowler AM, Solodin N, Preisler-Mashek MT, Zhang $\mathrm{P}$, Lee AV, Alarid ET. Increases in estrogen receptoralpha concentration in breast cancer cells promote serine 118/104/106-independent AF-1 transactivation and growth in the absence of estrogen. Faseb j. 2004. 18: 81-93.

42. Ali HR, Dawson SJ, Blows FM, Provenzano E, Pharoah PD, Caldas C. Aurora kinase A outperforms Ki67 as a prognostic marker in ER-positive breast cancer. $\mathrm{Br} \mathrm{J}$ Cancer. 2012. 106: 1798-1806.

43. Grontved L, Madsen MS, Boergesen M, Roeder RG, Mandrup S. MED14 tethers mediator to the N-terminal domain of peroxisome proliferator-activated receptor gamma and is required for full transcriptional activity and adipogenesis. Mol Cell Biol. 2010. 30: 2155-69.

44. Lindberg K, Strom A, Lock JG, Gustafsson JA, Haldosen LA, Helguero LA. Expression of estrogen receptor beta increases integrin alphal and integrin beta1 levels and enhances adhesion of breast cancer cells. J Cell Physiol.
2010. 222: 156-67.

45. Hung YC, Chang WC, Chen LM, Chang YY, Wu LY, Chung WM, Lin TY, Chen L C, Ma WL. Non-genomic estrogen/ estrogen receptor alpha promotes cellular malignancy of immature ovarian teratoma in vitro. J Cell Physiol. 2014. 229: 752-61.

46. Helguero LA, Lindberg $\mathrm{K}$, Gardmo $\mathrm{C}$, Schwend $\mathrm{T}$, Gustafsson JA, Haldosen LA. Different roles of estrogen receptors alpha and beta in the regulation of E-cadherin protein levels in a mouse mammary epithelial cell line. Cancer Res. 2008. 68: 8695-8704.

47. Gorodeski G. I. Estrogen decrease in tight junctional resistance involves matrix-metalloproteinase-7-mediated remodeling of occludin. Endocrinology. 2007. 148: 218231.

48. Zheng S, Huang J, Zhou K, Zhang C, Xiang Q, Tan Z, Wang T, Fu X. 17beta-Estradiol enhances breast cancer cell motility and invasion via extra-nuclear activation of actinbinding protein ezrin. PLoS One. 2011. 6: e22439.

49. Sotoca AM, Gelpke MD, Boeren S, Strom A, Gustafsson JA, Murk AJ, Rietjens IM, Vervoort, J. Quantitative proteomics and transcriptomics addressing the estrogen receptor subtype-mediated effects in T47D breast cancer cells exposed to the phytoestrogen genistein. Mol Cell Proteomics. 2011. 10: M110.0021701- M110.0021701.

50. Keen JC, Zhou Q, Park BH, Pettit C, Mack KM, Blair B, Brenner K, Davidson NE. Protein phosphatase 2A regulates estrogen receptor alpha (ER) expression through modulation of ER mRNA stability. J Biol Chem. 2005. 280: 29519-29524.

51. Ueda K, Lu Q, Baur W, Aronovitz MJ, Karas RH. Rapid estrogen receptor signaling mediates estrogen-induced inhibition of vascular smooth muscle cell proliferation. Arterioscler Thromb Vasc Biol. 2013. 33: 1837-1843.

52. Wu JT, Lin HC, Hu YC, Chien CT. Neddylation and deneddylation regulate $\mathrm{Cul1}$ and $\mathrm{Cul} 3$ protein accumulation. Nat Cell Biol. 2005. 7: 1014-1020.

53. Rodriguez-Gonzalez A, Cyrus K, Salcius M, Kim K, Crews CM, Deshaies RJ, Sakamoto KM. Targeting steroid hormone receptors for ubiquitination and degradation in breast and prostate cancer. Oncogene. 2008. 27: 7201-7211. 